\title{
EDITORIAL
}

\section{Confusing Inequitable Medicare Prescription Drug Benefit}

\author{
Gail E. Shearer, MPP \\ Consumers Union, 1101 17th Street, NW, Suite 500, Washington, District of Columbia 20036, USA.
}

DOI: $10.1007 / \mathrm{s} 11606-006-0080-5$

(C) 2007 Society of General Internal Medicine 2007;22:286-288

\section{INTRODUCTION}

Medicare beneficiaries enrolling in the new prescription drug coverage plans found that along with the financial relief came a dizzying array of choices inequities that result in very different coverage options and prices depending on where they live. This does not have to be the case. Taxpayers who foot $75 \%$ of the bill deserve the benefit of leveraging of public purchasing power. Medicare beneficiaries deserve a prescription drug option they can understand, that is uniform nationwide, that meets unexpected needs, and that achieves deep drug discounts.

\section{MARKETPLACE CONFUSION}

The choices a typical senior faces are many: a stand-alone plan or drug coverage through a Medicare advantage plan; copayment level and tier structure; deductible; formulary (which drugs are covered and the basis for selection); restrictions such as prior authorization; gaps in coverage, and many more. As the paper, "Variation in Estimated Medicare Prescription Drug Plan Costs and Affordability for Beneficiaries Living in Different States," by Davis et al. shows, the premiums that beneficiaries face for identical overage can vary widely by state -building in a new level of unfairness in Medicare, designed originally with a uniform benefit for which the key eligibility criteria was reaching age 65 .

Confusion in the marketplace can set the stage for fraud and abuse, the kind that occurred in the 1970s and 1980s when insurance agents exploited the fears of vulnerable seniors by selling them duplicative, overlapping policies to cover the gaps in Medicare. Too much choice can be counterproductive and overwhelming ${ }^{1}$. Medicare beneficiaries-especially those with impaired vision or no web-surfing experience - need a more rational marketplace, a simplified choice, and a seller they can trust.

A surplus of choice and confusion in the marketplace is a sign of breakdown of marketplace competition ${ }^{2}$. If Medicare beneficiaries were choosing the plans with the lowest costs and highest quality, then overpriced poorer quality plans should be forced out of the market. The proliferation of new plans and

Published online January 20, 2007 more choices for 2007, compared with 2006, combined with the failure of the government to provide useful comparative quality information, suggests that despite the existence of a powerful plan finder cost comparison tool, the forces of competition have not yet gone to work on behalf of Medicare beneficiaries.

An ideally functioning marketplace, though, will still not help everyone because one cannot predict getting cancer or a stroke and so fails to pick a plan that is "good" for that future disaster. Variations in benefit design result in a wide range of cost-sharing, with the percent difference between the lowest and highest cost Part D plans ranging from $47 \%$ (for metastatic breast cancer) to $2,740 \%$ (for metastatic colon cancer) ${ }^{3}$. How long can the nation's seniors and the disabled wait until the full benefits of a healthy competitive marketplace are achieved? How can cancer patients and others unable to predict future drug needs be protected against high out-ofpocket costs?

The 1990 OBRA reforms of the medigap marketplace showed that sound public policy-in that case simplification of a complex market through standardizing the benefit packages-can help this vulnerable population get better value for their health insurance dollar ${ }^{4,5}$. Congress should apply lessons from the medigap marketplace to the prescription drug marketplace, and provide seniors and the disabled with a uniform drug benefit that is easily understood, can be trusted, and can improve on coverage by putting the negotiating power of the federal government to work on behalf of this population.

\section{GEOGRAPHIC INEQUITIES}

The analysis by Davis et al. shows a high level of variation in prices for prescription drug plans: a patient (with serious chronic conditions) shopping for the lowest-priced plan in Florida will pay over $\$ 12,000$ more than the patient with identical drug needs) in Georgia. This newly introduced inequity is another in a series of steps that erodes the original design of the Medicare program, which was conceived as a program to provide uniform hospital and doctor coverage regardless of geography.

This is not the first time Congress created geographical inequities. The introduction of Medicare HMOs in the 1980s led to a departure from the nationwide uniform Medicare benefit and resulted in widely differing coverage in different parts of the country. The gradual introduction of private HMO coverage has both complicated the choices beneficiaries must make and introduced major variation because the coverage varies based on where you live. 
Whereas beneficiaries welcome expanded coverage, it has come at a high price in terms of fairness and government subsidization of private companies. The benefits that were sweetened recently by the Medicare Modernization Act (MMA) are the result of generous taxpayer-provided subsidies that mean that it costs Medicare more, not less, when a beneficiary enrolls in a private (vs. the traditional) Medicare plan. The cost of the extra payments (in excess of average fee-for-service costs) to Medicare Advantage plans is estimated to be $\$ 30$ billion over the 5-year period between 2007 and $2011^{6}$. Supporters of privatization, though, promote the myth that the private companies are the key to constraining costs. The Minnesota Senior Federation has shown the local impact of this misguided policy: in a study of the market just before the MMA, seniors in Minnesota would have to pay almost $\$ 300$ a month to get "extra" Medicare benefits that included prescription drugs, dental, vision, and hearing services that were free to seniors in parts of Florida, New York, and some other states ${ }^{7}$. Dr. John Wennberg and his colleagues have found Medicare costs (after adjusting for health status) are twice as high (or more) in some regions compared to others ${ }^{8}$. Medicare can address this inequity by restoring uniform benefits, starting with a uniform drug benefit option.

\section{SMALL DRUG DISCOUNTS}

Another disappointment is the new drug benefit's failure to attain large discounts on the prices paid. The 40 to 60 insurance companies (in each state) that create preferred drug lists and negotiate drug prices with pharmaceutical companies do not achieve the deep discounts that can be attained by putting the purchasing power of the federal government (or groups of states) to work. A Consumers Union study of drug prices in Broward County, Florida found that Medicare Part D drug prices are between 10 and 20\% lower than prices available at retail drug stores. In contrast, the Department of Veterans Affairs negotiates discounts that are over 50\% off retail prices ${ }^{9}$. States with evidence-based preferred drug lists and effective drug bidding processes have also achieved substantial savings for their Medicaid drug purchases. In Medicare Part D, premiums paid by beneficiaries cover $25 \%$ of the cost of the drug benefit; taxpayers are footing the bill for the other $75 \%$ and are paying the most of the cost of this failure to rein in drug costs.

States have also shown leadership in curbing prescription drug spending, while assuring Medicaid enrollees have access to the most effective, safe, and affordable medicines. A key ingredient in their success, and the VA's success with its drug formulary, is basing preferred drug lists on reports that show the comparative clinical effectiveness of drugs, and balance the need for flexibility with the goal of cost containment. The Oregon Health \& Science University-based Drug Effectiveness Review Project (DERP), now used by 15 states to help guide drug selection for their Medicaid programs, has developed a valuable database of systematic reviews, providing U.S. leadership for putting evidence-based medicine into practice by policymakers ${ }^{10}$. States are free to take local preferences with regard to restrictiveness of formulary versus cost containment in making use of such a database to achieve substantial savings ${ }^{11}$. Medicare beneficiaries and physicians can learn more about DERP findings through Consumer Reports Best Buy Drugs ${ }^{12}$, which translates the complex systematic reviews for the public, and provides information for free in English and Spanish for 16 categories of drugs including commonly used drugs for high blood pressure, high cholesterol, depression, allergies, and insomnia. Reliance of DERP-based Best Buy Drugs recommendations can help beneficiaries save thousands of dollars a year, in many cases helping them avoid the feared Medicare "doughnut hole" gap in coverage ${ }^{13}$.

\section{CONGRESS SHOULD FIX THE MEDICARE MODERNIZATION ACT}

Congress should act promptly to address the confusion and inequities in the Medicare drug program and provide beneficiaries with a drug coverage option that is uniform nationwide, creates a formulary based on evidence, negotiates deep discounts, and uses the savings to create a more rational benefit design that eliminates the "doughnut hole."

Medicare coverage should be uniform nationwide, with the drugs on the formulary selected because they are the most effective and safe, with minimal side effects. An evidence-based preferred drug list, paired with negotiation of deep discounts, would allow coverage (of drugs on the PDL) during the doughnut hole. An effective exceptions and appeals process would be available to those who need to go off formulary. Medicare beneficiaries deserve a prescription drug option that they can understand, that is uniform nationwide, with a rational benefit structure that provides fair coverage when unexpected needs arise, and with discounts that bring down the cost on behalf of those paying the premiums and taxpayers. Congress should make fixing the flawed Medicare law a top priority in 2007.

Acknowledgments: Gail Shearer, M.P.P. is director of Health Policy Analysis for the Washington Office of Consumers Union, and director of Consumer Reports Best Buy Drugs, a public education project that receives funding from The Engelberg Foundation, a private philanthropy, and the National Library of Medicine. The views expressed are those of Consumers Union and not the funders. Many thanks to Jessica Banthin, Lynn Ohman, and Bill Vaughan for their helpful comments.

Corresponding Author: Gail E. Shearer, MPP; Consumers Union, 1101 17th Street, NW, Suite 500, Washington, District of Columbia 20036, USA (e-mail: sheaga@consumer.org).

\section{REFERENCES}

1. Schwartz B. The paradox of choice-why more is less, Harper-Collins, 2004:26.

2. Scitovsky T. Ignorance as a source of oligopoly power. Am Econ Rev. 1950;40(2):48-53.

3. Harrison C, Nguyen Loa, Avalere Health LLC for The American cancer society. "Cost-Sharing for Cancer Patients in Medicare: Seven Case Studies," October 2006. http://www.avalerehealth.net.

4. Rice T, Thomas K. Evaluating the new Medigap Standardization Regulations. Health Aff. 1992;Spring:11(1)194-207. 
5. Fox PD, Snyder R, Dallek G, Rice T. Should Medicare HMO benefits be standardized?" Health Aff. 1999;18(4):40-52.

6. Biles B, Adrion E. Payments to Medicare Advantage Plans Exceed Feefor-Service Costs: Options for Medicare Savings from 2007 through 2011. Washington: George Washington University School of Public Health \& Health Services; September 15, 2006.

7. http://mnseniors.org/content/view/138/67/ Accessed 11-4-2006 and The Medicare Modernization Act of 2003: An Upper Midwest Policy paper, at mnseniors.org

8. Wennberg JE, Fisher ES, Skinner JS. Geography And The Debate Over Medicare Reform, Health Affairs, Web Exclusive, February 13, 2002.
9. Sikora P, Schiavone H. Consumers Union, Not Low Enough: Medicare Part D 'Donut Hole' Prices Compared with Retail and VA Prices, October 2006, http://www.consumersunion.org.

10. http://www.ohsu.edu/drugeffectiveness/.

11. Hartung DM, Ketchum KL, Haxby DG. An Evaluation of Oregon's Evidence-Based Practitioner-Managed Prescription Drug Plan. Health Affairs. 2006;25(5) September/October.

12. http://www.CRBestBuyDrugs.org.

13. Medicare Prescription Drug Benefit: Beneficiaries Can Lower Out-ofPocket Costs While Getting Safe and Effective Drugs, Consumers Union, March 2, 2006, at http://www.CRBestBuyDrugs.org. 